\title{
PERFORMANCE EVALUATION OF COMPOSITE FIBRE INCORPORATED IN A SLAG BASED CONCRETE MATRIX
}

\author{
[J.Vikram]
}

\begin{abstract}
Researchers focused on the study of mechanical behavior of fibre reinforced concrete in a detailed manner. Recent studies were made concentrating on the long term durability properties of the fibre reinforced concrete. The synergistic effect of fibre concrete which consists of two or more fibres shows a correspondingly better performance than single fibre addition. The present study focused on the drying shrinkage and effect on the compressive property due to freeze and thaw cycle. Two types of fibres such as steel and polypropylene fibres were used and a slag based concrete matrix is designed. Long term performance of this slag based hybrid fibre concrete depends on the types, size and dosage of fibre added to the concrete matrix. The test results show a significant variation for different mixes of concrete.
\end{abstract}

Keywords: slag, steel, polypropylene, synergy, shrinkage.

Vikram Jothijayakumar (Corresponding Author) Assistant Professor, Ammini College of Engineering, Palakkad, Kerala, INDIA.

+919843142188

\section{Introduction}

The concrete mix proportions were conceptually arrived based on the packing density of the concrete materials considering $50 \%$ coarse aggregate and 50\% mortar. Ordinary Portland cement confirming IS 12269-1987 locally available river sand belonging to Zone II of IS383-1970 is used. Locally available aggregate of size $12.5 \mathrm{~mm}$ and $20 \mathrm{~mm}$ size conforming IS383-1970 were used in this study.

The long term performance studies were made on hybrid mixes which focus on the drying shrinkage of control and hybrid concrete mixes [1-2]. This paper also deals with the specimens subjected to freeze and thaw cycle. High range water reducing plasticizer is used to increase the workability of the concrete as water/cement ratio is maintained as 0.3 . The fibres are added in percentage volume fraction of the volume of mortar. Longer and shorter combination of steel $(60 \mathrm{~mm}$ $\& 35 \mathrm{~mm})(\mathrm{SF})$ and polypropylene $(47 \mathrm{~mm} \& 23.5 \mathrm{~mm})(\mathrm{PP})$ fibres were used.

\section{Drying Shrinkage}

Shrinkage is an important factor which is to be considered for concrete long term performance. Specimen of control concrete 
and hybrid mixes where casted and measure of micro-strain with respect to number of days is observed and tabulated. Figure 1 shows the experimental set up to evaluate dry shrinkage of all the concrete mixes.

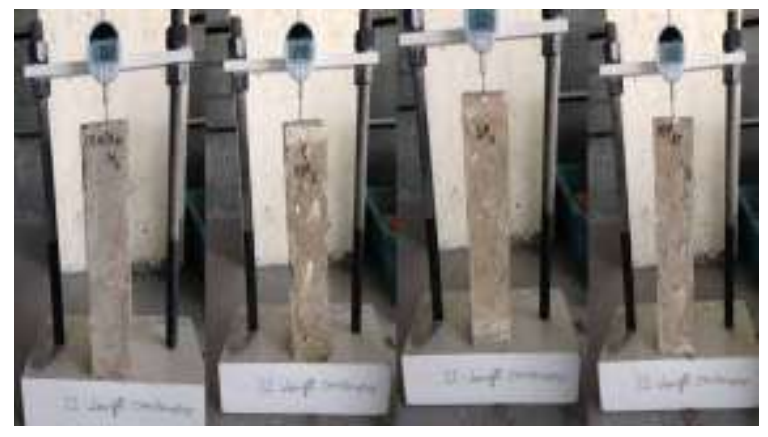

Figure 1 Drying shrinkage evaluation of different specimens

Figure 2 shows the graphical representation of the dry shrinkage of all the concrete mixes. It clearly shows all the hybrid mixes reduces the rate of shrinkage with respect to time. Mix HYF35 incorporating $40 \%$ of $23.5 \mathrm{~mm}$ PP and $60 \%$ of $35 \mathrm{~mm}$ controls the rate of shrinkage when compared to other mixes.

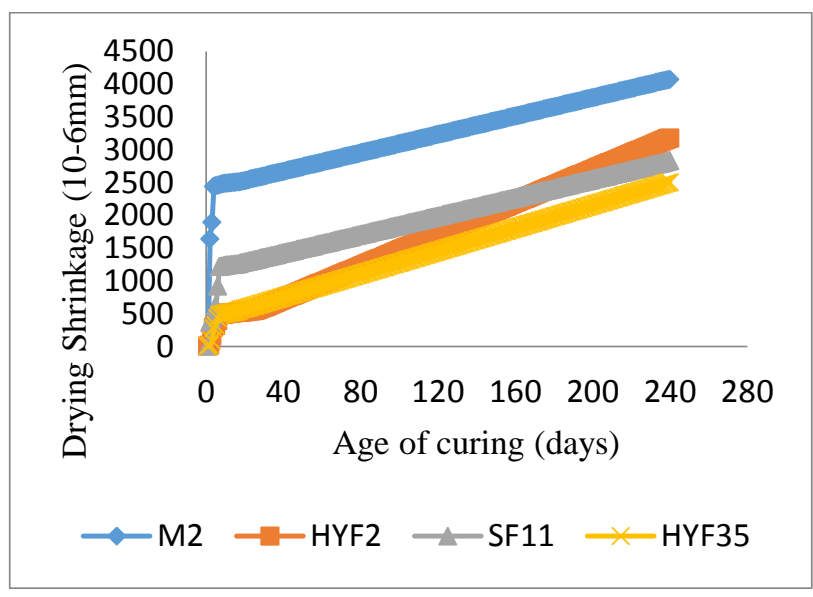

Figure 2. Drying shrinkage of control and hybrid mixes

\section{Freeze And Thaw Cycle} Cube specimens of $150 \mathrm{~mm}$ were casted, placed 2 hours in humidity chamber at $8^{\circ} \mathrm{C}$ and immersed in water for 2 hours. This cycle is repeated again and then after the specimen is placed under normal water for 16 hours. The water accumulated in the pores is subjected to cyclic freezing and de-freezing which caused wear in the concrete. Figure 3 shows the humidity chamber with test specimens.
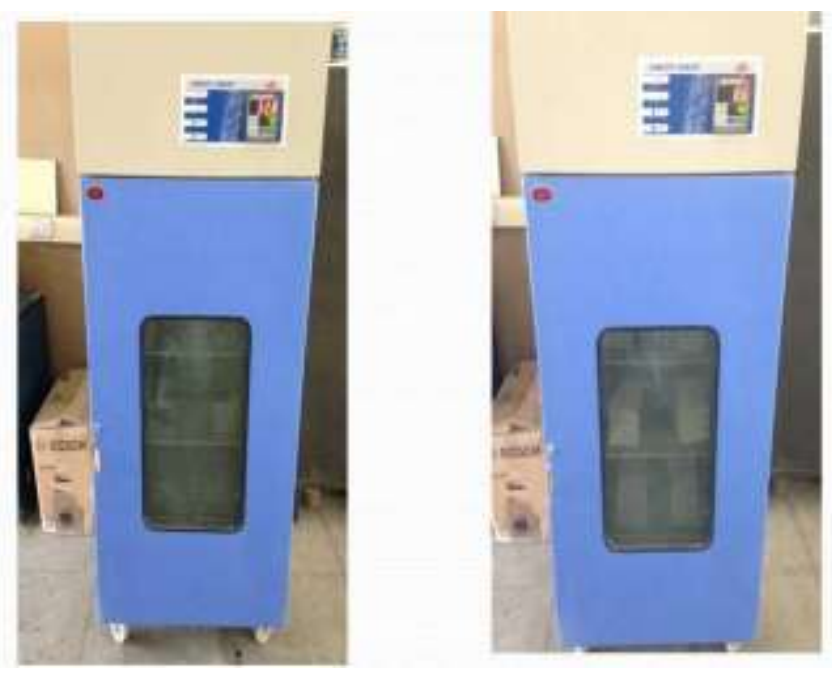

Figure 3. Specimens placed in humidity chamber to freeze and thaw cycle.

Figure 4 shows the test results of control and hybrid mixes under freeze-thaw cycle. The strength loss is evaluated and found that application of shorter fibres in mix HYF35 has recorded lesser strength loss compared to other specimens. 


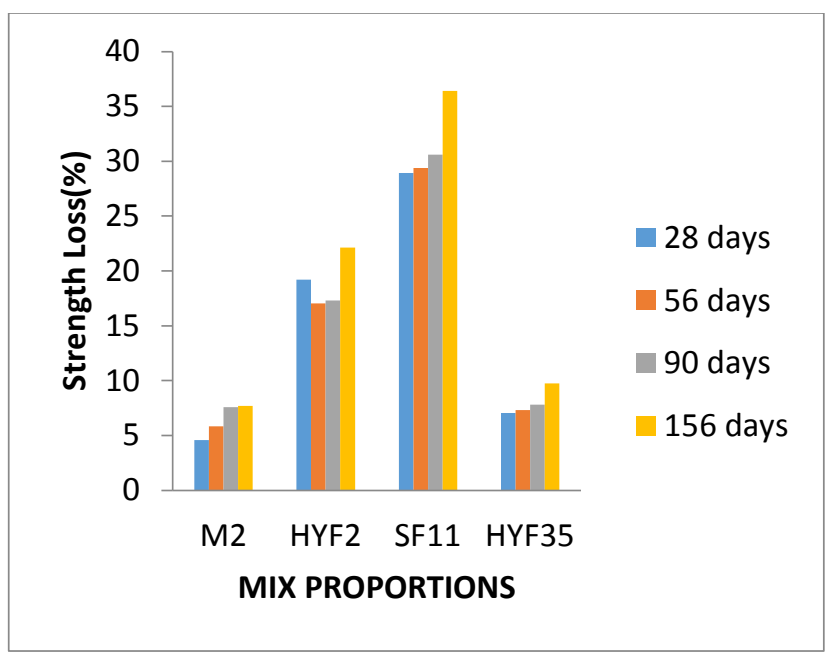

Figure 4 Strength loss of different concrete specimens subjected to freeze and thaw cycle

\section{Conclusions}

The following conclusion may be arrived with the limitations from the test conducted in structural engineering lab.

Drying shrinkage results shows that mix HYF35 with shorter fibres records a better control over shrinkage and mix HYF2 records a similar pattern. SF11 also shows a better value than control concrete M2.

$>$ Defects due to freeze and thaw cycle are also controlled better by HYF35 than other hybrid mixes.

The application of hybrid combination shows a better performance than single fibre addition.

\section{References}

[1]. Won JP, Hwang KS, Park CG, Park HG(2004). Evaluation of Crack Control and Permeability of Hydrophilic PVA Fiber Reinforced Cement Composite. Journal of Korea Concrete Institute, Vol. 16, No. 2, pp. 391-396.

[2]. Kim MH, Kim JH, Kim YR, Kim YD(2005). An Experimental Study on the Mechanical Properties of HPFRCCs Reinforced with the Micro and Macro Fibers. Journal of Korea Concrete Institute, Vol. 17, No. 2, pp. 263-271. 